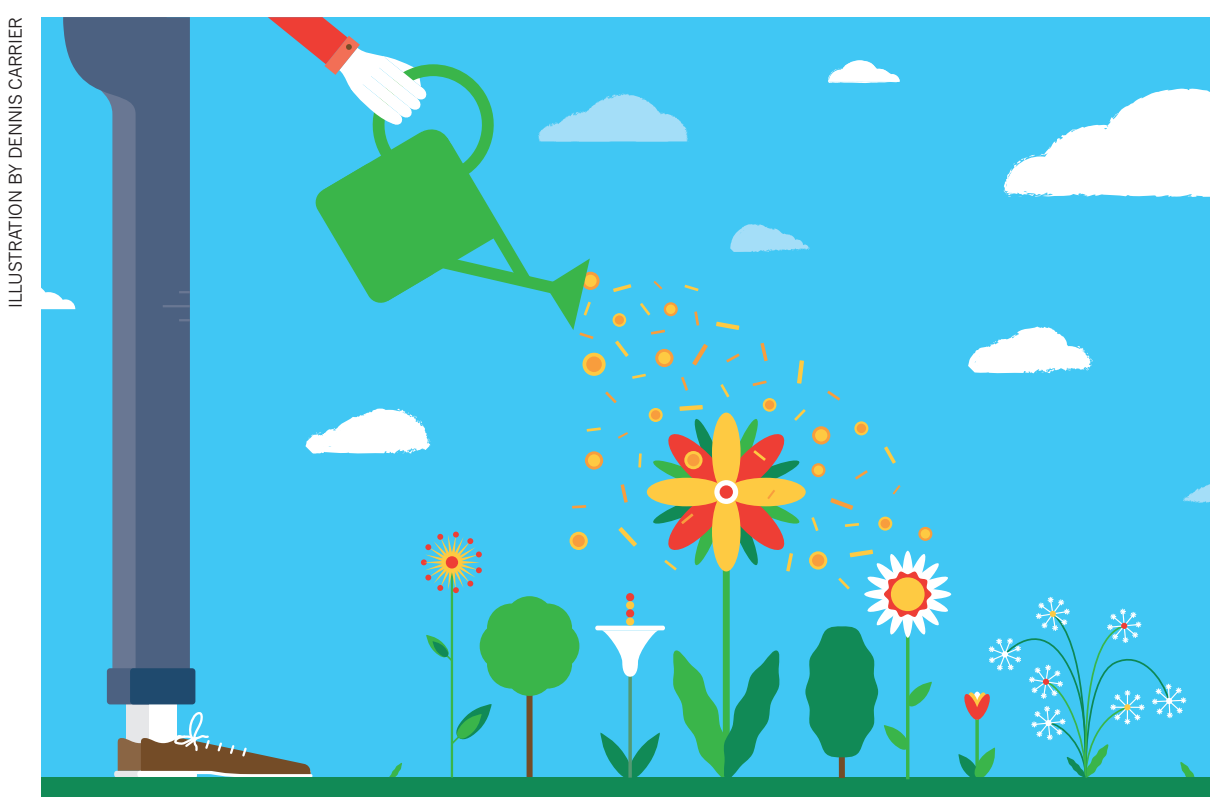

\title{
Set research priorities in a time of recession
}

\section{Rigorous analyses are needed to establish the benefits of the knowledge economy, says former Irish government science adviser Patrick Cunningham.}

$\mathrm{M}$ any governments say that they are using the current recession to refocus their public investment in science and technology. But after analysing countries' declarations of their research and development (R\&D) funding and objectives to the Organisation for Economic Co-operation and Development (OECD) over the past decade, I have found that, in fact, not much has changed.

Nineteen of the 34 OECD member states have fully and consistently reported their civil R\&D expenditure in the past two decades. Twelve of these have cut their public science budgets since 2007 (see go.nature. com/5dzkjp). Others have maintained modest growth. There have been exceptional annual funding increases in South Korea, a dramatic one-year stimulus in 2009 in the United States, and a European Union (EU) commitment to a $28 \%$ increase for its $2014-$ 2020 budget. But research directions have remained the same.

I believe that all nations should use this time of change to improve the way that public funds are deployed in science. We need to learn from best practice at individual, institutional, corporate, national and international levels. To do so will require ongoing analysis of the facts, and a more rigorous scientific approach to science policy.

Today, most OECD countries direct less than $1 \%$ of their tax revenues to R\&D. This still amounts to substantial budgets under public control. The United States and the EU are responsible for half of the world's roughly US $\$ 1,400$-billion investment in R\&D, despite being home to only $12 \%$ of its population.

Industry and businesses spend twice as much on R\&D as governments do, split among thousands of enterprises. Despite this, the real driver of business innovation can be public expenditure: in the United States, the technological base of companies such as Apple, Intel, Google and much of the pharmaceutical industry is rooted in publicly funded research ${ }^{1}$.

Governments vary widely in how they aim their R\&D investment. The United States stands out as directing more than half of its budget to defence. By contrast, the EU spends 95\% of its R\&D investment on civil aims. Almost all other reporting countries had civil R\&D fractions of more than $90 \%$ in 2011.

Civil R\&D objectives as declared to the OECD fall into three classes: economic development, in sectors such as agriculture, industry and energy; specific public-good objectives, including health, environment, education, social and space programmes; and non-oriented, or basic, research and general university funds. One might expect governments to favour economic impact in this time of austerity, but the OECD records show little shift in research spending focus.

Between 2006 and 2012, just one country out of 19 increased the amount it spent on economic objectives by more than $10 \%$ : Ireland (where I was the government's chief scientific adviser from 2007-2012) raised such spending by $13 \%$ to support innovation, growth and employment in the agriculture, food, marine and industrial sectors. And the country's business $\mathrm{R} \& \mathrm{D}$ expenditure rose by $43 \%$ between 2006 and 2010, although cause and effect are difficult to disentangle.

Most countries invested $20-30 \%$ of their science budget in economic development in 2011. South Korea, the highest such spender, targeted $50 \%$ as part of a purposeful and successful partnership between government and big business. Belgium and, with recently modernized economies, Finland and Ireland, spent just under $40 \%$ on economic development (see 'Civil spending shifts'). In the 1990s, Finland powered its way to economic recovery by increasing public investment in $\mathrm{R} \& \mathrm{D}$, and, despite the recent travails of Finnish communications company Nokia, the country has weathered the latest recession better than most.

Countries with relatively low economicdevelopment investment include the United States (11\% in 2012) and the United Kingdom (8\%), with large contributions to universities and defence.

The US and EU approaches to spending are radically different. Whereas the EU (taking into account each country's spending plus central European spending) directs more than half of its total civil R\&D budget to non-oriented research and general university funding, most of the US civil R\&D expenditure $(73 \%)$ goes to health and environment programmes (see 'Different priorities').

In the United States, almost all public R\&D funding comes directly from Washington DC, and this centralized system facilitates the scale, depth and continu-

ity of programmes.

"Industry and The more diffuse businesses spend twice as much on R\&D as governments." European funding structure can lead to duplication, but competition and diversity aid the spread of innovative ideas. Just $7 \%$ of EU research investment is channelled through Brussels, although this might rise to $10 \%$ under Horizon 2020, the next EU research and innovation funding cycle that will run from 2014 to 2020 .

The overall level of US and EU spending on $R \& D$ has changed little in the past decade; it is still too early to judge the impact of the \$20-billion spike in US-government 


\section{CIVIL SPENDING SHIFTS}

Countries including South Korea, Ireland and Finland have focused their civil research and development investment on economic development, in areas such as energy and industry.

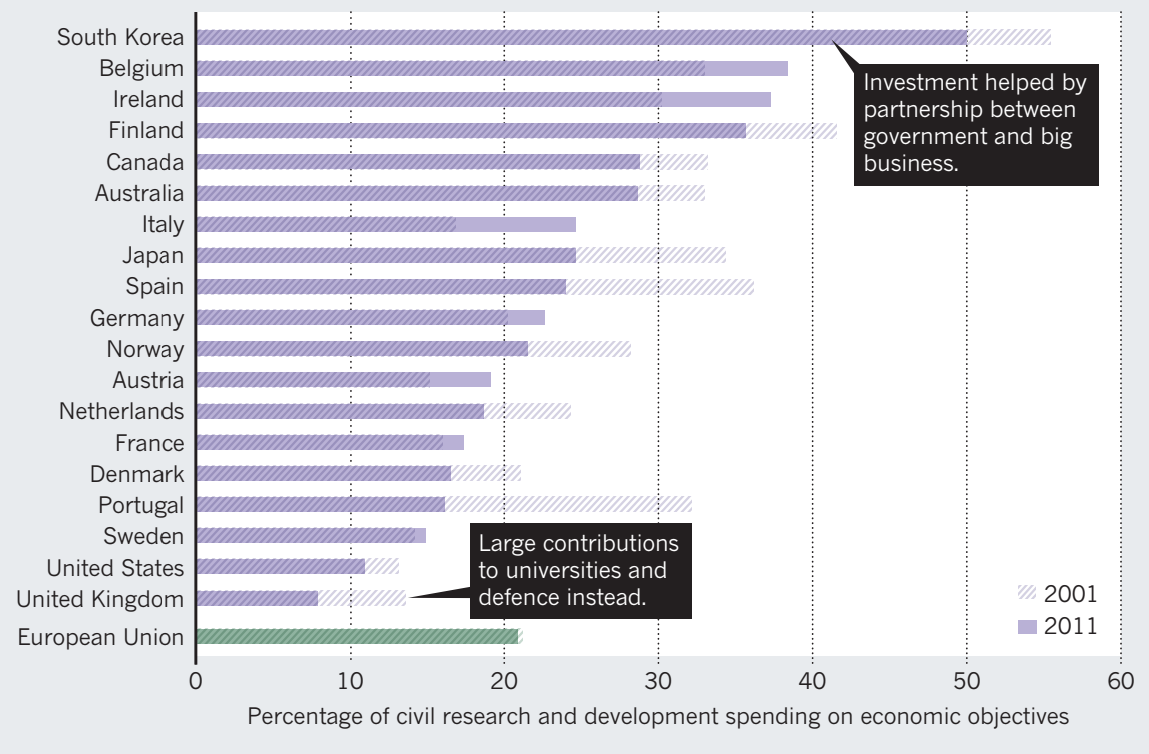

R\&D funds (a 14\% hike) in 2009. In 2000, the ambition of the EU Lisbon Strategy to spend $3 \%$ of gross domestic product (GDP) by 2010 on public and private R\&D combined was achieved by only three countries: Finland, Sweden and Denmark. For the EU as a whole, the figure is under $2 \%$. And at just under $0.7 \%$, public investment is still well below the Lisbon target of $1 \%$.

Evaluating the impacts of $\mathrm{R} \& \mathrm{D}$ is challenging because they might not be felt until many years after the publication of research, and credit is difficult to apportion. The main challenges are to clarify the timescales involved and to quantify the trade-offs and synergies among inputs, outputs and interactions with parallel developments in other countries and in the business sector.

Better models and metrics need to be developed to measure the inputs, outputs and progress of the knowledge economy. The US Science of Science Policy initiative ${ }^{2}$ (see scienceofsciencepolicy.net), which was proposed in 2005 by physicist and presidential science adviser John Marburger ${ }^{3}$, has made a start. Some 150 research contracts have been awarded to analyse the social and administrative structures of research programmes and their links with sectors of society. But the US focus is on its centralized structures.

\section{PICK PRIORITIES}

Europe, where the flows of many smaller national investments need to be understood, lags behind in science-policy analysis. Data collected by the OECD and Eurostat have informed cross-country studies, such as the Innovation Union Scoreboard ${ }^{4}$ that assembles 25 indicators into an innovation index. Countries such as China, Japan, South Korea and Taiwan also lack substantial sciencepolicy analysis programmes.

In this time of recession, when taxpayers are asked to invest their hard-earned money for the public good, all governments need to reassess the aims of their R\&D budgets. Each nation must decide its own priorities; the experiences of Ireland and Finland suggest that there is much to be gained by investing explicitly for economic development - the benefits might be evident within a few years. The merits of defence research require debate.

The level of R\&D funding needs to be raised across the board. EU governments

\section{DIFFERENT PRIORITIES}

Public research and development budgets are skewed towards defence in the United States and mainly towards civil programmes in Europe.

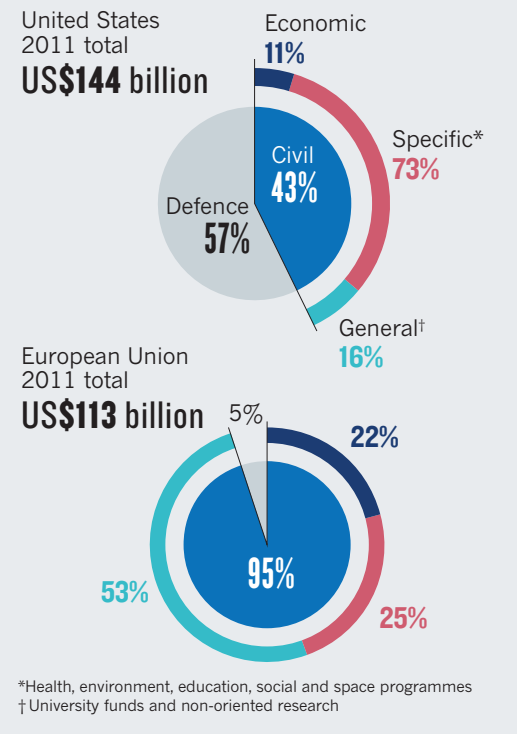

should recommit to the Lisbon Strategy goal and boost their public funding of $\mathrm{R} \& \mathrm{D}$ to $1 \%$ of GDP as soon as possible. Private investment should follow with encouragement, as in Ireland.

Better economic models are needed to understand the impacts of investments in different areas. These could follow the framework set out in two World Bank reports ${ }^{5,6}$ that consider natural resources, produced goods and services, and intangible social and intellectual value capital analogously to economist Adam Smith's 'land, labour and capital'. The first two are readily measured; the last is hard to evaluate but constitutes most of the wealth in developed societies.

In the meantime, GDP growth is a reasonable aim for R\&D investment. Although it will not deliver all of the benefits that society desires, it correlates closely with broader measures such as the Human Development Index and Satisfaction with Life Index. GDP is thus not an end in itself, but an enabler of multiple end points.

To understand linkages between R\&D investment and societal benefit, the 'science of science policy' field must be developed. The EU's 28 national programmes deserve attention because they constitute a rolling experiment in building knowledge economies. A series of workshops and joint research calls is needed to bring scientists and economists together to study the effects.

Europe will benefit from pooling its diverse experiences to get better value from the more than $90 \%$ of its R\&D spend that is locked into national budgets. By strengthening links between researchers and institutions, perhaps through the EU Joint Programming Initiative, EU countries will gain more from Horizon 2020 than the financial contributions they make.

Most of the public science budget is invested in people, and most research is conducted by young scientists who move on to deploy their knowledge and skills throughout the economy. Governments must acknowledge that R\&D is the driver of future welfare, security and prosperity.

Patrick Cunningham is professor of animal genetics at Trinity College Dublin, Ireland. From 2007 to 2012 he was chief scientific adviser to the Irish government. e-mail:epcnnghm@tcd.ie

1. Mazzucato, M. The Entrepreneurial State (Anthem, 2013).

2. Lane, J. Nature 464, 488-489 (2010).

3. Marburger, J. H. Science 308, 1087 (2005).

4. European Commission. Innovation Union Scoreboard 2013 (EC, 2013); available at http:// go.nature.com/sxvo7d.

5. World Bank. Where is the Wealth of Nations? (World Bank, 2006); available at http:// go.nature.com/xr2iju.

6. World Bank. The Changing Wealth of Nations (World Bank, 2011); available at http:// go.nature.com/n3j3sj. 